\title{
A Genome-Wide Analysis of Antibiotic Producing Genes in Streptomyces globisporus SP6C4
}

\author{
Da-Ran Kim $^{1}$ and Youn-Sig Kwak (D) 1,2* \\ ${ }^{I}$ Research Institute of Life Science, Gyeongsang National University, Jinju 52828, Korea \\ ${ }^{2}$ Division of Applied Life Science (BK21Plus) and IALS, Gyeongsang National University, Jinju 52828, Korea
}

(Received on March 17, 2021; Revised on April 5, 2021; Accepted on April 7, 2021)

Soil is the major source of plant-associated microbes. Several fungal and bacterial species live within plant tissues. Actinomycetes are well known for producing a variety of antibiotics, and they contribute to improving plant health. In our previous report, Streptomyces globisporus SP6C4 colonized plant tissues and was able to move to other tissues from the initially colonized ones. This strain has excellent antifungal and antibacterial activities and provides a suppressive effect upon various plant diseases. Here, we report the genome-wide analysis of antibiotic producing genes in $S$. globisporus SP6C4. A total of 15 secondary metabolite biosynthetic gene clusters were predicted using antiSMASH. We used the CRISPR/Cas9 mutagenesis system, and each biosynthetic gene was predicted via protein basic local alignment search tool (BLAST) and rapid annotation using subsystems technology (RAST) server. Three gene clusters were shown to exhibit antifungal or antibacterial activity, viz. cluster 16 (lasso peptide), cluster 17 (thiopeptide-lantipeptide), and cluster 20 (lantipeptide). The results of the current study showed that SP6C4 has a variety of antimicrobial activities, and this strain is beneficial in agriculture.

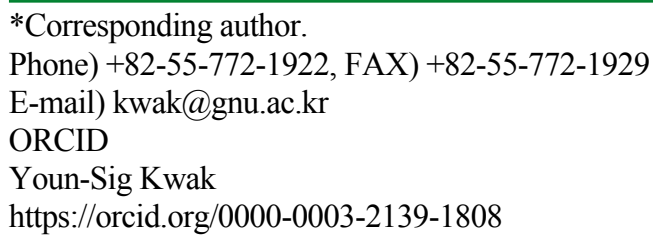

(c) This is an Open Access article distributed under the terms of the Creative Commons Attribution Non-Commercial License (http:// creativecommons.org/licenses/by-nc/4.0) which permits unrestricted noncommercial use, distribution, and reproduction in any medium, provided the original work is properly cited.

Articles can be freely viewed online at www.ppjonline.org.
Keywords : antifungal, antibacterial, lantibiotic, lassopeptide, Streptomyces

The members of genus Streptomyces are a soil bacterium that produce various bioactive compounds (Bentley et al., 2002; Deshpande et al., 1988; Durán et al., 2018; Lee et al., 2020). Nearly $80 \%$ of the antibiotics used by humans are produced by Streptomyces (Durán et al., 2018; Harir et al., 2018; Hu et al., 2018). Many secondary metabolites produced by Streptomyces have antibacterial, antifungal, and anticancer properties (Genilloud, 2017; Gomes et al., 2017; Oskay, 2009). The genera Bacillus, Lactobacillus, Enterococcus, Streptococcus, and Lactococcus are known to produce ribosome-synthesized antibiotic peptides such as lantibiotics and bacteriocins (Cotter et al., 2005; Dischinger et al., 2009; Jabés et al., 2011). Nonribosomal peptide synthetase (NRPS) and polyketide synthase (PKS) metabolites are synthesized by large enzymatic complexes that are mostly produced by the order Actinomycetales and Bacillus species (Ansari et al., 2004). Furthermore, the genus Streptomyces produce two-thirds of natural antibiotics, antitumor agents, and immune suppressors (Maiti et al., 2020).

The presence of Streptomyces spp. has been verified in the phyllosphere, rhizosphere, and endosphere of plants. The phyllosphere has recently drawn attention for being an important microbial habitat (Lindow and Brandl, 2003; Redford et al., 2010). In our previous study, Streptomyces globisporus strain S4-7 was well characterized as a responsible agent for the soil suppressiveness of Fusarium wilt of strawberry. This suggested the involvement of heat tolerance compounds and action in disease suppression (Cha et al., 2016). S. globisporus strain S4-7 produced a novel thiopeptide, conprimycin, which has several macrocyclic ring systems consistent with other thiopeptides (Cha et al., 2016). The bioactive conprimycin produced by S4-7 
Table 1. Putative antibiotic gene clusters in Streptomyces globisporus SP6C4 predicted by antiSMASH

\begin{tabular}{lcllr}
\hline Group $^{\mathrm{a}}$ & Cluster $^{\mathrm{b}}$ & \multicolumn{1}{c}{ Type } & \multicolumn{1}{c}{ Most similar known cluster } & \multicolumn{1}{c}{ Similarity (\%) } \\
\hline A & 1 & NRPS-T1PKS & Daptomycin biosynthetic gene & 7 \\
& 5 & NRPS-T1PKS & Bottromycin A2 biosynthetic gene & 100 \\
& 8 & NRPS-T1PKS & Griseobactin biosynthetic gene & 100 \\
B & 13 & NRPS-T1PKS & SGR_PTMs biosynthetic gene & 11 \\
& 2 & T3PKS & Collismycin A biosynthetic gene & - \\
& 24 & T3PKS & Enduracidin biosynthetic gene & 11 \\
C & 30 & T1PKS & - & 6 \\
& 18 & NRPS & Tetonasin biosynthetic gene & 100 \\
& 25 & NRPS & Herboxidiene biosynthetic gene & 40 \\
D & 29 & NRPS & C-1027 biosynthetic gene & 7 \\
& 12 & Lantipeptide & Amfs biosynthetic gene & - \\
& 15 & Lantipeptide & Labyrinthopeptin A1/A2/A3 biosynthetic gene & 100 \\
\hline
\end{tabular}

NRPS-T1PKS, nonribosomal peptide synthetase-type I polyketide synthase; T3PKS, type III peptide synthetase; NRPS, nonribosomal peptide synthetase.

${ }^{a}$ Group assigned by molecular backbone of product. Note Figs. 1 and 2.

${ }^{b}$ Cluster represents the order of biosynthesis genes.

inhibits fungal cell wall biosynthesis and RNA polymerase activity (Cha et al., 2016). In addition, another antifungal lantipeptide gene (lanM) was identified and named grisin (Kim et al., 2019b).

The genome of the bacterial strain used in this study has been reported by using shotgun genome sequencing (Cha et al., 2016) and PacBio genome sequencing reported by Kim et al. (2019a). We used antiSMASH (Medema et al., 2011) to predict the secondary metabolite gene clusters in this strain. The 15 predicted antibiotic-related genes were divided into groups of linked NRPS-PKS, PKS, ribosomal protein synthase-lantipeptide, and thiopeptide (Table 1, Fig. 1). Analysis of gene expression by real-time quantitative reverse transcription-polymerase chain reaction revealed that members of the antibiotic-related genes were reliably expressed, except for cluster 13 (Fig. 2A, Supplementary Table 1). To amplify the left arm (LA) and right arm (RA) regions for each target gene by CRISPR-Cas 9 mutagenesis, SP6C4 genomic DNA $(1 \mu \mathrm{g})$ and gene-specific primers were used (Supplementary Table 2). For each gene, (1) LA and RA regions were amplified using PCR under the following conditions: initial denaturation (at $98^{\circ} \mathrm{C}$ for $10 \mathrm{~min}$ ) followed by 30 cycles of denaturation (at $98^{\circ} \mathrm{C}$ for $1 \mathrm{~min}$ ), annealing (at $52-58^{\circ} \mathrm{C}$ for $30 \mathrm{~s}$, respective primer tm), elongation (at $72^{\circ} \mathrm{C}$ for $30 \mathrm{~s}$ ), and final extension $\left(\right.$ at $72^{\circ} \mathrm{C}$ for 5 $\mathrm{min}$ ); (2) the LA and RA regions were linked by PCR (initial denaturation [at $98^{\circ} \mathrm{C}$ for $30 \mathrm{~s}$ ], five cycles for denaturation [at $98^{\circ} \mathrm{C}$ for $8 \mathrm{~s}$ ], annealing [at $50^{\circ} \mathrm{C}$ for $30 \mathrm{~s}$ ], elongation [at $72^{\circ} \mathrm{C}$ for $30 \mathrm{~s}$ ], and extension [at $72^{\circ} \mathrm{C}$ for $5 \mathrm{~min}$ ]); and (3) the target homologous regions including LA and RA were amplified (the final PCR step was similar to [1] LA and RA region PCR conditions, which changed the annealing temperature to $60^{\circ} \mathrm{C}$ ). PCR was performed using MJ Research PTC-200 Thermal Cycler (Bio-Rad, Hercules, CA, USA). The amplicons were loaded onto a $1 \%$ agarose gel and eluted in $30 \mu \mathrm{l}$ of elution buffer (EB buffer) (Expin GelSV kit, GeneAll Biotechnology, Seoul, Korea). A-tailing was performed with $100 \mathrm{mM}$ of deoxyadenosine triphosphate (dATP) (NEB, Ipswich, MA, USA) at $70^{\circ} \mathrm{C}$ for $30 \mathrm{~min}$, the solution was purified with 5 volumes of GB buffer (Expin GelSV kit) and eluted in $20 \mu \mathrm{l}$ of EB buffer. The purified molecule was ligated to a pGEM-T easy vector (Promega, Madison, WI, USA) with T4 ligase (Promega) by overnight incubation at $16^{\circ} \mathrm{C}$ and then transformed into Escherichia coli DH5 $\alpha$. Transformants were detected by blue/white colony selection on LB medium (Luria broth $30 \mathrm{~g}$, agar 20 $\mathrm{g} / \mathrm{l})$ with ampicillin $(100 \mu \mathrm{g} / \mathrm{ml})$ and 5-bromo-4-chloro-3indolyl- $\beta$-D-galactopyranoside (X-gal, $40 \mu \mathrm{g} / \mathrm{ml}$ ). Plasmids in white colonies were extracted using DokDo-Prep plasmid mini-prep kit (ELPIS-Biotech, Daejeon, Korea). Next, the vector and pCRISPomyces-gRNA (Cobb et al., 2015) were cut using $X b a \mathrm{I}$ (NEB, Ipswich, MA, USA), eluted in $30 \mu \mathrm{l}$ of EB buffer, and a 3:1 ratio ligation was performed with 400,000 units (400 units/ $\mu$ l) of T4-ligase (NEB). The gRNA was cloned into pBHA (2,002 bp), the pCRISPomyces- 2 was cut with $B b s I$ (NEB), and the two fragments 

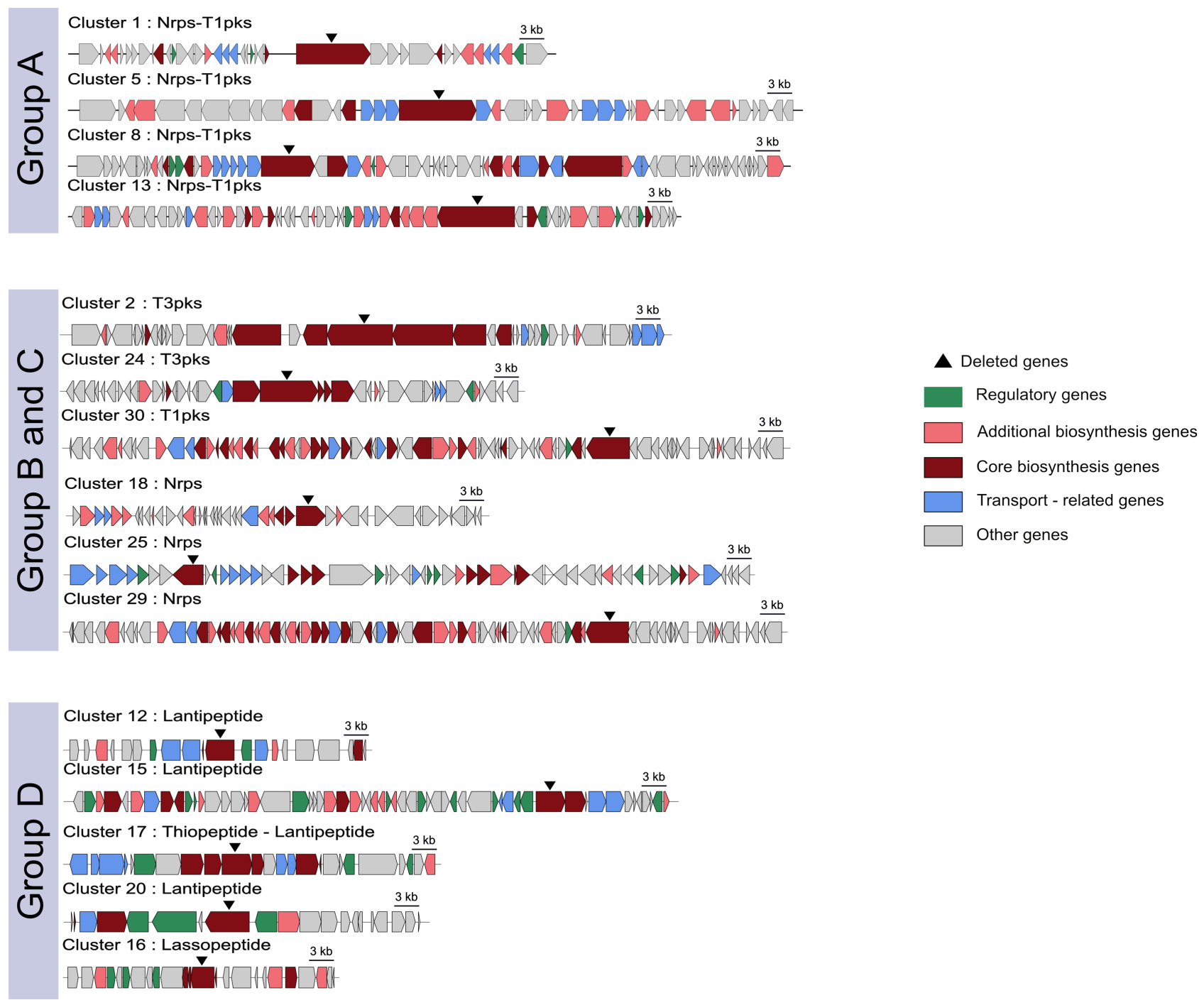

Fig. 1. Schematic representation of deleted gene using CRISPR/Cas9 system. Left penal shows the distribution of gene functions and CRISPR/Cas9 targeted deletion sites. Group A was NRPS-PKS linked clusters, groups B and C were PKS and NRPS groups. Group D had lantipeptide and lassopeptide clusters. The cluster was characterized using antiSMASH version 4.0.0rc1 (https://antismash.secondarymetabolites.org/).

were ligated with $\mathrm{T} 4$ ligase and ligated again with the guide RNA (gRNA). The resulting plasmid was transformed into $E$. coli ET12567 containing pUZ8002 (Bierman et al., 1992), and transformants were recovered on LB agar containing kanamycin $(30 \mu \mathrm{g} / \mathrm{ml})$, chloramphenicol $(25 \mu \mathrm{g} /$ $\mathrm{ml})$, and apramycin $(50 \mu \mathrm{g} / \mathrm{ml})$ (Kieser et al., 2000). For seed cultures (E. coli ET12567/pUZ8002), single colonies were inoculated in LB broth containing the three antibiotics, then transferred to $10 \mathrm{ml}$ of LB broth containing the antibiotics and incubated at $37^{\circ} \mathrm{C}$ for $9 \mathrm{~h}$ with shaking at $150 \mathrm{rpm}$. The cultured cells were first centrifuged $(1,914$ $\times g$ for $15 \mathrm{~min}$ ), then gently washed two times in $10 \mathrm{ml} \mathrm{LB}$ broth, centrifuged again, and thereafter suspended in $500 \mu \mathrm{l}$ of LB broth. In a separate Eppendorf tube, $500 \mu \mathrm{l}$ of $2 \times$ YT medium was heated to $50^{\circ} \mathrm{C}$ for $10 \mathrm{~min}$ and mixed with 10 $\mu \mathrm{l}$ of a spore stock of SP $6 \mathrm{C} 4\left(10^{9} \mathrm{cfu} / \mathrm{ml}\right)$ in $20 \%$ glycerol. The washed E. coli cells were added to the SP6C4 spore stock, mixed with a pipette, and spread on PDK agar (potato dextrose [Difco, Franklin Lakes, NJ, USA] 24 g, peptone $10 \mathrm{~g}$, agar $20 \mathrm{~g} / \mathrm{l})$. After $16 \mathrm{~h}$, apramycin $(50 \mu \mathrm{g} / \mathrm{ml})$ and nalidixic acid $(25 \mu \mathrm{g} / \mathrm{ml})$ were overlaid on the plates, and 7 days later, colonies were transferred two times onto PDK agar containing apramycin $(50 \mu \mathrm{g} / \mathrm{ml})$. Finally, each mutant was confirmed by PCR. All mutagenized strains and plasmids are shown in Table 2.

Except for the 14-cluster mutant strain, all other mutant 

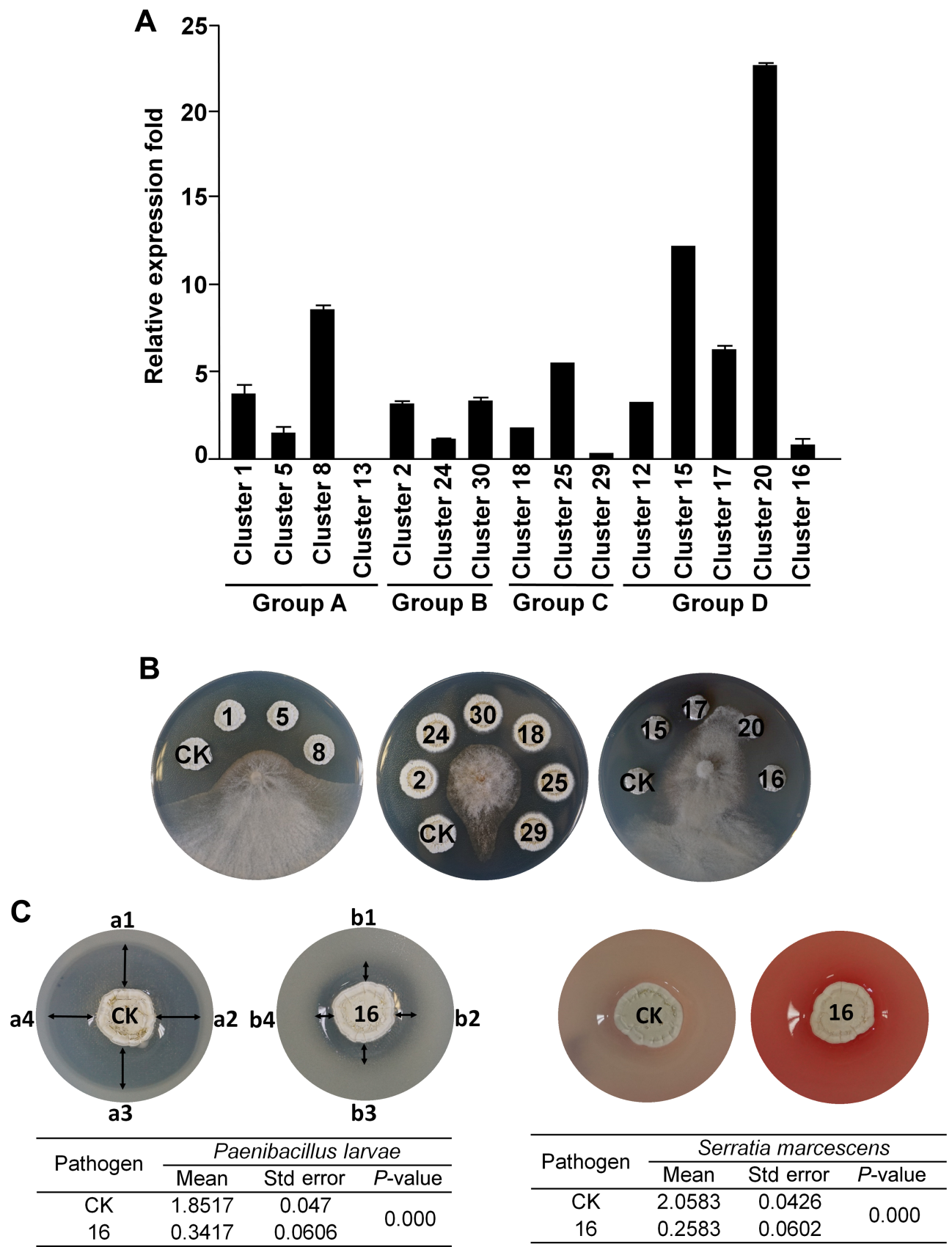

\begin{tabular}{cccc}
\hline \multirow{2}{*}{ Pathogen } & \multicolumn{3}{c}{ Paenibacillus larvae } \\
\cline { 2 - 4 } & Mean & Std error & $P$-value \\
\hline CK & 1.8517 & 0.047 & 0 \\
16 & 0.3417 & 0.0606 & 0.000 \\
\hline
\end{tabular}

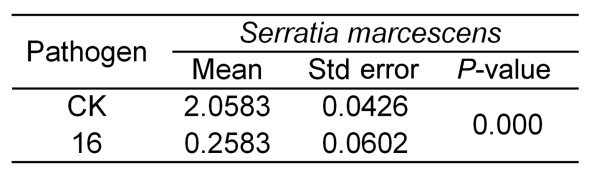

Fig. 2. Antibiotic activity and related gene clusters in SP6C4. (A) Putative antibiotic gene clusters were predicted by antiSMASH, group A (NRPS-PKS), group B (NRPS), group C (PKS), group D (lantipeptide and lassopeptide). Relative gene expression levels were analyzed by qPCR. recA served as a housekeeping gene and primer information is presented in Supplementary Table 1. Bars represent standard error. (B) Antifungal activity of knockout mutants against $B$. cinerea. The mutants were created by the CRISPR/Cas9 system. The mutants $(10 \mu 1$ on a $0.8 \mathrm{~cm}$ filter disk) were incubated in PDK. After 5 days, an agar block of $B$. cinerea $(0.4 \mathrm{~cm}$ diameter) was inoculated at the center of the plate and incubated at $28^{\circ} \mathrm{C}$ for 7 days $(n=5)$. CK represent the SP6C4 strain treatment and the numbers on the disc indicate each mutant based on the cluster number. (C) Paenibacillus larvae and Serratia marcescens served as entomopathogens. A two-layer method was employed to evaluate antibacterial activity. SP6C4 (10 $\mathrm{cfu} / \mathrm{ml}, 10 \mu \mathrm{l})$ was inoculated on PDK medium. The entomopathogens were mixed into $25 \mathrm{ml}$ of pre-cooled $0.2 \% \mathrm{PDK}$ and overlaid onto the probiotic plates (final entomopathogen concentration was $\left.10^{5} \mathrm{cfu} / \mathrm{ml}\right)$. The overlaid plates were incubated at $28^{\circ} \mathrm{C}$ for 5 days and the size of the inhibition zone was measured (CK, al to a4; 16 cluster deletion mutants, b1 to b4). Entomopathogen inhibition test data were analyzed using one-way ANOVA, $P$-value less than 0.05 indicates that the size of the inhibition zones from $\mathrm{CK}$ and 16 was significantly different. 
Table 2. Bacteria and plasmids used in this study

\begin{tabular}{|c|c|c|}
\hline Strains/Plasmids & Description & Reference \\
\hline \multicolumn{3}{|l|}{ Escherichia coli } \\
\hline $\mathrm{DH} 5 \alpha$ & $\begin{array}{l}\mathrm{F}-, \text { } \Phi 80 \mathrm{~d} l a c Z \Delta \mathrm{M} 15,(\mathrm{lacZYA}-\operatorname{argF}) \mathrm{U} 169, \text { deoR, recA1, endA1, hsdR17 (rk-, mk+), } \\
\text { phoA, supE44, } \lambda-\text {, thi-1, gyrA96, relA1 }\end{array}$ & Bierman et al. (1992) \\
\hline ET12567/pUZ8002 & $\begin{array}{l}\text { dam-13::Tn9 } d c m-6 h s d M \text {, carries RK2 derivative with defective oriT for plasmid } \\
\text { mobilization, } \operatorname{Kan}^{\mathrm{r}}\end{array}$ & Bierman et al. (1992) \\
\hline \multicolumn{3}{|l|}{ Streptomyces SP6C4 } \\
\hline SP6C4.lanA & SP6C4 $\Delta$ lanA::Apra ${ }^{\mathrm{r}}$ & Kim et al. (2019b) \\
\hline SP6C4. lanB & SP6C4 $\Delta l a n B::$ Apra $^{\mathrm{r}}$ & Kim et al. (2019b) \\
\hline SP6C4. lanC & SP6C4 $\Delta$ lanC:: Apra $^{\mathrm{r}}$ & Kim et al. (2019b) \\
\hline SP6C4. lanL-1 & SP6C4 DlanL-1:: Apra $^{\mathrm{r}}$ & Kim et al. (2019b) \\
\hline SP6C4. lanL-2 & SP6C4 DlanL-2:: Apra $^{\mathrm{r}}$ & Kim et al. (2019b) \\
\hline SP6C4. lanM & SP6C4 DlanM:: Apra ${ }^{\mathrm{r}}$ & Kim et al. (2019b) \\
\hline SP6C4. $t s r D$ & SP6C4 tsrD:: Apra $^{\mathrm{r}}$ & Kim et al. (2019b) \\
\hline SP6C4. nrps - pks 1 & SP6C4 nrps - pks $1::$ Apra $^{\mathrm{r}}$ & This study \\
\hline SP6C4. nrps -pks 5 & SP6C4 nrps -pks $5::$ Apra $^{\mathrm{r}}$ & This study \\
\hline SP6C4. nrps -pks 8 & SP6C4 nrps -pks $8::$ Apra $^{\mathrm{r}}$ & This study \\
\hline SP6C4.pks 2 & SP6C4 pks $2::$ Apra $^{\mathrm{r}}$ & This study \\
\hline SP6C4. pks 24 & SP6C4 pks $24::$ Apra $^{\mathrm{r}}$ & This study \\
\hline SP6C4. pks 30 & SP6C4 pks $30::$ Apra $^{\mathrm{r}}$ & This study \\
\hline SP6C4. nrps 18 & SP6C4 nrps $18::$ Apra $^{\mathrm{r}}$ & This study \\
\hline SP6C4. nrps 24 & SP6C4 nrps $24::$ Apra $^{\mathrm{r}}$ & This study \\
\hline SP6C4. nrps 29 & SP6C4 nrps $29::$ Apra $^{\mathrm{r}}$ & This study \\
\hline SP6C4. lasso 17 & SP6C4 lasso $17::$ Apra $^{\mathrm{r}}$ & This study \\
\hline \multicolumn{3}{|l|}{ Plasmid/Cosmid } \\
\hline pCRISPomyces-2 & $A m^{\mathrm{r}}$, oriT $\operatorname{rep}^{\mathrm{pSG} 5(\mathrm{ts})}$, ori $^{\mathrm{ColE} 1}$, sSpcas 9 , sgRNA cassette & Cobb et al. (2015) \\
\hline pBHA & $\mathrm{Am}^{\mathrm{r}}, \mathrm{pUC}$ ori, gRNA clone & Bioneer, Korea \\
\hline pCRSP.nrps-pks 1 & pCRISPomyces- $2+\Delta$ nrps-pks 1 editing template, $n r p s-p k s 1$ sgRNA $-s S p c a s 9$ & This study \\
\hline pCRISP.nrps-pks 5 & pCRISPomyces- $2+\Delta$ nrps-pks 5 editing template, $n r p s-p k s 5$ sgRNA $-s S p c a s 9$ & This study \\
\hline pCRISP.nrps-pks 8 & pCRISPomyces- $2+\Delta$ nrps-pks 8 editing template, $n r p s-p k s 8$ sgRNA $-s S p c a s 9$ & This study \\
\hline pCRISP.pks 2 & pCRISPomyces- $2+\Delta$ pks 2 editing template, pks 2 sgRNA $-s$ Spcas 9 & This study \\
\hline pCRISP.pks 24 & pCRISPomyces- $2+\Delta$ pks 24 editing template, pks $24 \operatorname{sgRNA}-s$ Spcas 9 & This study \\
\hline pCRISP.pks 30 & pCRISPomyces- $2+\Delta$ pks 30 editing template, pks $30 \operatorname{sgRNA}-s \operatorname{spcas} 9$ & This study \\
\hline pCRISP.nrps 18 & pCRISPomyces- $2+\Delta$ nrps 18 editing template, $n r p s 18$ sgRNA $-s S p c a s 9$ & This study \\
\hline pCRISP.nrps 24 & pCRISPomyces- $2+\Delta$ nrps 24 editing template, nrps $24 \operatorname{sgRNA}-s \operatorname{Spcas} 9$ & This study \\
\hline pCRISP.nrps 29 & pCRISPomyces- $2+\Delta$ nrps 29 editing template, nrps 29 sgRNA - sSpcas 9 & This study \\
\hline pCRISP.lasso 17 & pCRISPomyces- $2+\Delta$ lasso 17 editing template, lasso 17 sgRNA - sSpcas 9 & This study \\
\hline
\end{tabular}

strains showed no difference in growth and sporulation from the wild-type strains (data not shown). Antifungal Streptomyces mutant lines were confirmed using a plate assay. First, a single colony was streaked on PDK medium and cultured at $28^{\circ} \mathrm{C}$ for 5 days. Then the bacterial spore stock was collected with a sterilized cotton ball and filtered using a 10-ml syringe. Spore colony forming units were counted on PDK agar medium and $10 \mu \mathrm{l}$ of samples were dropped onto $8 \mathrm{~mm}$ diameter paper disks on PDK agar.
After sporulation (5 days post inoculation), $4 \mathrm{~mm}$ diameter plugs of actively growing mycelia of Botrytis cinerea were placed in the center of the plates. Fungal inhibition was evaluated after 7 days. This screening was repeated with 5 plates in each antiSMASH group and activity was defined as -, no inhibition; + (low inhibition), 0.1-0.5 cm; ++ (medium inhibition), 0.5-1 cm; +++ (strong inhibition), 1-1.5 $\mathrm{cm}$; ++++ (maximum inhibition), $>1.5 \mathrm{~cm}$. Only the mutants in lantipeptide clusters 17 (tsrD, Conprimycin) and 20 
(lanM, Grisin) were significantly less inhibitory to the gray mold pathogen (Fig. 2B). These results indicate that lantipeptide genes in the microbe play a major role in antifungal activity.

A two-layer method was used to evaluate the antibacterial activity against entomopathogenic bacteria, Paenibacillus larvae, and Serratia marcescens. Streptomyces strains were suspended to give $10^{6} \mathrm{cfu} / \mathrm{ml}$, and thereafter $10 \mu \mathrm{l}$ was inoculated onto a $0.8 \mathrm{~cm}$ filter disk on PDK agar. P. larvae and $S$. marcescens were cultured in PDK broth for 3 days at $28^{\circ} \mathrm{C}$, followed by mixing of $5 \mathrm{ml}$ culture of each pathogen into $25 \mathrm{ml}$ of pre-cooled $0.2 \%$ PDK agar and overlaying them onto plates. The plates were dried for $30 \mathrm{~min}$, incubated at $28^{\circ} \mathrm{C}$ for 5 days, and antibacterial activity was indicated by the size of the inhibition zone around the disk. The entomopathogen growth inhibition assay was repeated five times as replications and analysis of variance (ANOVA) followed by Tukey's honestly significant difference (Tukey's honestly significant difference) $(P=0.05)$ for mean separation. All graphs were visualized using ggplots version 3.0.1, and ggplot2 version 2.1.0 in the $\mathrm{R}$ software package. A mutant in cluster 16, encoding a lassopeptide, was less active against entomopathogenic bacteria (Fig. 2C). These findings support the hypothesis that the strain SP6C4 carries an arsenal of antibiotics needed to provide dual protection to plants and pollinators (Kim et al., 2019a).

The bacterial isolate in the rhizosphere has antifungal activity against strawberry gray mold fungal pathogens (Cha et al., 2016; Kim et al., 2019a). Studies on Streptomyces functional genes have rarely been conducted before using the CRISPR-Cas9 system. In this study, we used the CRISPR-Cas9 system (which is faster than homologous mutagenesis) to target mutagenesis, which involves the investigation of functional genes at a genome-wide scale. Moreover, our findings improved our understanding of the SP6C4 strain.

\section{Conflicts of Interest}

Youn-Sig Kwak serves as Editor-in-Chief for the Plant Pathology Journal, but has no role in the decision to publish this article. The remaining author has declared no conflicts of interest.

\section{Acknowledgments}

This research was supported by an agenda research program funded by the Rural Development Administration (PJ15871) and the Next-Generation BioGreen 21 Program (PJ013250).

\section{Electronic Supplementary Material}

Supplementary materials are available at The Plant Pathology Journal website (http://www.ppjonline.org/).

\section{References}

Ansari, M. Z., Yadav, G., Gokhale, R. S. and Mohanty, D. 2004. NRPS-PKS: a knowledge-based resource for analysis of NRPS/PKS megasynthases. Nucleic Acids Res. 32:W405W413.

Bentley, S. D., Chater, K. F., Cerdeño-Tárraga, A.-M., Challis, G. L., Thomson, N. R., James, K. D., Harris, D. E., Quail, M. A., Kieser, H., Harper, D., Bateman, A., Brown, S., Chandra, G., Chen, C. W., Collins, M., Cronin, A., Fraser, A., Goble, A., Hidalgo, J., Hornsby, T., Howarth, S., Huang, C.-H., Kieser, T., Larke, L., Murphy, L., Oliver, K., O’Neil, S., Rabbinowitsch, E., Rajandream, M.-A., Rutherford, K., Rutter, S., Seeger, K., Saunders, D., Sharp, S., Squares, R., Squares, S., Taylor, K., Warren, T., Wietzorrek, A., Woodward, J., Barrell, B. G., Parkhill, J. and Hopwood, D. A. 2002. Complete genome sequence of the model actinomycete Streptomyces coelicolor A3(2). Nature 417:141-147.

Bierman, M., Logan, R., O'Brien, K., Seno, E. T., Rao, R. N. and Schoner, B. E. 1992. Plasmid cloning vectors for the conjugal transfer of DNA from Escherichia coli to Streptomyces spp. Gene 116:43-49.

Cha, J.-Y., Han, S., Hong, H.-J., Cho, H., Kim, D., Kwon, Y., Kwon, S.-K., Crüsemann, M., Lee, Y. B., Kim, J. F., Giaever, G., Nislow, C., Moore, B. S., Thomashow, L. S., Weller, D. M. and Kwak, Y.-S. 2016. Microbial and biochemical basis of a Fusarium wilt-suppressive soil. ISME J. 10:119-129.

Cobb, R. E., Wang, Y. and Zhao, H. 2015. High-efficiency multiplex genome editing of Streptomyces species using an engineered CRISPR/Cas system. ACS Synth. Biol. 4:723-728.

Cotter, P. D., Hill, C. and Ross, R. P. 2005. Bacterial lantibiotics: strategies to improve therapeutic potential. Curr. Protein Pept. Sci. 6:61-75.

Deshpande, B. S., Ambedkar, S. S. and Shewale, J. G. 1988. Biologically active secondary metabolites from Streptomyces. Enzyme Microb. Technol. 10:455-473.

Dischinger, J., Josten, M., Szekat, C., Sahl, H.-G. and Bierbaum, G. 2009. Production of the novel two-peptide lantibiotic lichenicidin by Bacillus licheniformis DSM 13. PLoS ONE 4:e6788.

Durán, P., Thiergart, T., Garrido-Oter, R., Agler, M., Kemen, E., Schulze-Lefert, P. and Hacquard, S. 2018. Microbial interkingdom interactions in roots promote Arabidopsis survival. Cell 175:973-983.

Genilloud, O. 2017. Actinomycetes: still a source of novel antibiotics. Nat. Prod. Rep. 34:1203-1232.

Gomes, K. M., Duarte, R. S. and de Freire Bastos, M. D. C. 2017. Lantibiotics produced by Actinobacteria and their potential applications (a review). Microbiology (Reading) 163:109- 
121.

Harir, M., Bendif, H., Bellahcene, M., Fortas, Z. and Pogni, R. 2018. Streptomyces secondary metabolites. In: Basic biology and applications of actinobacteria, ed. by E. Shymaa, pp. 99122. IntechOpen, London, UK.

Hu, D., Chen, Y., Sun, C., Jin, T., Fan, G., Liao, Q., Mok, K. M. and Lee, M.-Y. S. 2018. Genome guided investigation of antibiotics producing actinomycetales strain isolated from a Macau mangrove ecosystem. Sci. Rep. 8:14271.

Jabés, D., Brunati, C., Candiani, G., Riva, S., Romanó, G. and Donadio, S. 2011. Efficacy of the new lantibiotic NAI-107 in experimental infections induced by multidrug-resistant Grampositive pathogens. Antimicrob. Agents Chemother. 55:16711676.

Kieser, T., Bibb, M. J., Buttner, M. J., Chater, K. F. and Hopwood, D. A. 2000. Practical Streptomyces genetics. John Innes Foundation, Norwich, UK. 613 pp.

Kim, D.-R., Cho, G., Jeon, C.-W., Weller, D. M., Thomashow, L. S., Paulitz, T. C. and Kwak, Y.-S. 2019a. A mutualistic interaction between Streptomyces bacteria, strawberry plants and pollinating bees. Nat. Commun. 10:4802.

Kim, D.-R., Jeon, C.-W., Shin, J.-H., Weller, D. M., Thomashow, L. and Kwak, Y.-S. 2019b. Function and distribution of a lantipeptide in strawberry Fusarium wilt disease-suppressive soils. Mol. Plant-Microbe Interact. 32:306-312.

Lee, N., Hwang, S., Kim, J., Cho, S., Palsson, B. and Cho, B.-K. 2020. Mini review: genome mining approaches for the identification of secondary metabolite biosynthetic gene clusters in Streptomyces. Comput. Struct. Biotechnol. J. 18:1548-1556.

Lindow, S. E. and Brandl, M. T. 2003. Microbiology of the phyllosphere. Appl. Environ. Microbiol. 69:1875-1883.

Maiti, P. K., Das, S., Sahoo, P. and Mandal, S. 2020. Streptomyces sp SM01 isolated from Indian soil produces a novel antibiotic picolinamycin effective against multi drug resistant bacterial strains. Sci. Rep. 10:10092.

Medema, M. H., Blin, K., Cimermancic, P., de Jager, V., Zakrzewski, P., Fischbach, M. A., Weber, T., Takano, E. and Breitling, R. 2011. antiSMASH: rapid identification, annotation and analysis of secondary metabolite biosynthesis gene clusters in bacterial and fungal genome sequences. Nucleic Acids Res. 39:W339-W346.

Oskay, M. 2009. Antifungal and antibacterial compounds from Streptomyces strains. Afr. J. Biotechnol. 8:3007-3017.

Redford, A. J., Bowers, R. M., Knight, R., Linhart, Y. and Fierer, N. 2010. The ecology of the phyllosphere: geographic and phylogenetic variability in the distribution of bacteria on tree leaves. Environ. Microbiol. 12:2885-2893. 